\title{
Examination of Perceived Neighborhood Characteristics and Transportation on Changes in Physical Activity and Sedentary Behavior: The Trial of Activity in Adolescent Girls
}

\author{
Kelly R. Evenson ${ }^{1}$, David M. Murray², Amanda S. Birnbaum ${ }^{3}$, and Deborah A. Cohen 4 \\ ${ }^{1}$ University of North Carolina - Chapel Hill, Gillings School of Global Public Health, Department of \\ Epidemiology, Chapel Hill, NC \\ ${ }^{2}$ The Ohio State University, College of Public Health, Division of Epidemiology, Columbus, $\mathrm{OH}$ \\ ${ }^{3}$ Montclair State University, Department of Health and Nutrition Sciences, Montclair, NJ \\ ${ }^{4}$ RAND Corporation, Santa Monica, CA
}

\begin{abstract}
We examined the association between perceived neighborhood characteristics and transport and 2year changes in accelerometer-determined nonschool MET-weighted moderate to vigorous physical activity (MW-MVPA) and sedentary behavior of adolescent girls. Reporting that children do not play outdoors in their neighborhood, that their neighborhood was well lit, and that there were trails in their neighborhood were each associated with significant decreases in nonschool MW-MVPA. None of the neighborhood or transportation measures was associated with changes in nonschool sedentary behavior. Further work is needed to understand the determinants of the decline in physical activity and the increase in sedentary behavior among adolescent girls.
\end{abstract}

\section{Keywords}

environment; intervention; recreation; transportation; youth

\section{Introduction}

National surveillance indicates that physical activity among youth is suboptimal (Brownson et al., 2005; Matthews et al., 2008; Troiano et al., 2008) and significantly declines during the middle school years (Nader et al., 2008). To develop interventions to address this problem, it is important to identify factors associated with decreasing physical activity. The socioecologic framework may help in this regard, as it posits that physical activity behavior is influenced at the intrapersonal, interpersonal, neighborhood, policy, and environmental levels (McLeroy et al., 1988; Sallis and Owen, 1997). The neighborhood environment may be a particularly salient influence on physical activity among youth, since they have less

(C) 2010 Elsevier Ltd. All rights reserved.

Address for Correspondence: Kelly R. Evenson, Department of Epidemiology, Gillings School of Global Public Health, University of North Carolina - Chapel Hill, 137 East Franklin Street, Bank of America Center, Suite 306, Chapel Hill, NC 27514,

kelly_evenson@unc.edu; fax: 919-966-9800.

Publisher's Disclaimer: This is a PDF file of an unedited manuscript that has been accepted for publication. As a service to our customers we are providing this early version of the manuscript. The manuscript will undergo copyediting, typesetting, and review of the resulting proof before it is published in its final citable form. Please note that during the production process errors may be discovered which could affect the content, and all legal disclaimers that apply to the journal pertain. 
choice over where to play and be active (Ferreira et al., 2007). In support of this, in 2009 the American Academy of Pediatrics released a policy statement promoting environments and policies favoring physical activity, such as consideration of traffic, safety, and easier access to parks, open space, and schools (Tester, 2009).

A 2000 review of correlates of physical activity for youth found neighborhood or environmental factors to be an under-studied area (Sallis et al., 2000). Since that review, many more studies have explored this topic, often using cross-sectional designs and selfreported measures of physical activity (Biddle et al., 2005; Davison and Lawson, 2006; Ferreira et al., 2007; Van Der Horst et al., 2007). Ferreira et al (Ferreira et al., 2007) concluded that the question of how environmental features influence youth physical activity remains largely unanswered, in part due to the study designs employed by the existing studies.

The limitations on the existing literature on youth physical activity generally apply to the literature on sedentary behavior as well. A review of sedentary behavior among youth concluded that more research was needed to develop effective interventions to diminish time spent on inactive behaviors (Van Der Horst et al., 2007).

We previously studied the cross-sectional relationships between perceived neighborhood factors and physical activity and sedentary behavior (both occurring after school and on weekends, heretofore referred to as "nonschool") among 6th grade girls participating in the Trial of Activity in Adolescent Girls (TAAG) (Evenson et al., 2007). We identified several self-reported neighborhood factors associated with higher nonschool MET-weighted moderate-to-vigorous physical activity (MW-MVPA) in those cross-sectional analyses, including reporting well lit streets in the neighborhood, a lot of neighborhood traffic, presence of bicycle or walking trails in the neighborhood, and access to physical activity facilities. However, no cross-sectional associations between perceived neighborhood factors and sedentary behavior were identified.

The purpose of this study was to examine the prospective association between perceived neighborhood characteristics and transport (both assessed at baseline) on changes in nonschool MW-MVPA and sedentary behavior among a cohort of ethnically diverse adolescent girls. We hypothesized that girls who perceived a more conducive neighborhood environment for physical activity, more physical activity opportunities, and better transport options at baseline would have more favorable changes from 6th to 8th grade in nonschool physical activity and sedentary behavior.

\section{Methods}

\section{Study Population, Recruitment, and Consent}

At baseline, participants were adolescent girls in the 6th grade recruited from 36 schools located in Arizona, California, Louisiana, Maryland, Minnesota, and South Carolina who were participating in TAAG. TAAG was a multicenter school-based group-randomized trial designed to test an intervention to reduce the usual decline in physical activity among middle-school girls (Stevens et al., 2005; Webber et al., 2008). Parents or guardians provided written informed consent, and the girls also provided written assent. This study was approved by the Institutional Review Boards at each field center, the Coordinating Center, and at RAND.

Public middle schools in which a majority of students lived in the surrounding community were eligible to participate. Additional school eligibility criteria included: (1) enrollment of at least 90 8th-grade girls, (2) yearly withdrawal rates less than 28\%, (3) at least one 
semester of physical education required for each grade, and (4) willingness to sign a memorandum of understanding and accept random assignment of the school. TAAG schools represented the demographic and socioeconomic make-up of their school districts, with preference given to schools with greater racial/ethnic and socioeconomic diversity. Of the 68 schools invited to participate, 41 agreed and the 36 most conveniently accessed from the university-based research centers were selected (Elder et al., 2008).

\section{Data Collection Procedures}

Measurements considered here were taken during spring 2003 and 2005. Separate intervention and measurement staff were employed, and separate central training sessions were held to train and certify staff. These certified staff then trained additional site staff as needed. Periodic recertification ensured that performance standards were met.

Physical Activity and Sedentary Behavior Measures-An Actigraph (model \#AM7164) accelerometer was used to measure physical activity and sedentary behavior at baseline and follow-up. This device is made by Manufacturing Technologies Inc. Health Systems (http://mtiactigraph.com) and is a small, lightweight, technically reliable (Metcalf et al., 2002) uniaxial accelerometer. Participants wore the monitor on their right hip secured by a belt to measure accelerations in the vertical plane. Trained and certified TAAG staff members distributed the accelerometers and provided detailed verbal and written instructions on when and how to wear the accelerometers over a 6-day period. Girls were asked to remove the monitor only for sleeping, bathing, or swimming. Data were collected and stored in 30-second epochs. Half-minute counts were used instead of full-minute counts based on the expectation that the shorter interval would be more sensitive to fluctuations in activity levels.

Accelerometer readings were reduced using methods previously described (Treuth et al., 2004). If counts were recorded as zero for 20 minutes or more, then it was assumed that the participant was not wearing the accelerometer. We called girls compliant with the protocol if they wore the monitor $80 \%$ of the time available in a given block of time. The time blocks included before school, during school, after school, early evening, and evening. If the participant was compliant during the time block, we used the data provided and if not, we used imputation (based on the expectation maximization algorithm) to fill in the missing data for that block, with at least one day of compliance being required for each girl. The result was a set of six 18-hour days of data for each girl, covering the period from 6:00am to midnight. A separate evaluation of the imputation procedure indicated that it provided valid results, even when data were not missing at random (Catellier et al., 2005).

Sedentary behavior was defined as $0-50$ counts per 30-second epoch. Readings above 1500 counts per 30-seconds were defined as MVPA. This threshold for MVPA had the optimal sensitivity and specificity for discriminating brisk walking from less vigorous activities in 8th-grade girls (Treuth et al., 2004). Counts above 1500 per half-minute were converted into METs (metabolic equivalents) using a regression equation developed from a TAAG substudy (Schmitz et al., 2005; Treuth et al., 2004); the sum of METs over a single day provided MET-minutes per day of MVPA, where 1 MET-minute represents the metabolic equivalent of energy expended sitting at rest for 1 minute. This provided more weight to vigorous activities when compared to moderate activities. For example, an activity corresponding to 7 METs performed for 10 minutes would receive a value of $70 \mathrm{MW}$ MVPA minutes. For the analyses, accelerometer data were limited to after school on weekdays (2:00pm to midnight) and on weekends, because we hypothesized that the neighborhood environmental factors and transportation would only affect nonschool 
activity; the accelerometer data were summed over the six days measured for each girl. We also repeated the analyses when including the weekday morning time (6:00am-9:00am).

Self-reported Neighborhood and Transportation Measures-Self-reported measures of neighborhood environment were taken from a questionnaire developed during the pilot phase of the TAAG Study (Evenson et al., 2006) and completed in both $6^{\text {th }}$ and $8^{\text {th }}$ grades, close to the time of accelerometry data collection. Ten items asked about perceived safety (e.g., safe to walk or jog in neighborhood, see walkers/bicyclists from homes on street, traffic, crime, other children playing outdoors, lighting), aesthetics (i.e., many interesting things to look at in the neighborhood), and access to facilities near home (e.g., places to walk to from home, sidewalks, trails). For each of the 10 items, the response options on a 5-point scale were disagree a lot, disagree a little, neither agree or disagree (referred to as "neutral" in the text and tables), agree a little, or agree a lot. Two-week testretest reliability, on a separate sample of 6th- and 8th- grade girls, using the 5-level responses ranged from 0.37-0.58 (weighted kappa coefficients) for these items (Evenson et al., 2006). For analysis, these 5-level answers were collapsed into three categories based on distributions and to increase reliability: disagree, neutral, and agree. We chose a priori to analyze each of the items separately.

Girls were provided a list of 14 facilities and asked: "Is it easy to get to and from this place from home or school?" (yes or no). The listed facilities included the following: basketball court, beach or lake, golf course, health club, martial arts studio, playing field (soccer or softball), park, recreation center or YMCA/YWCA, track, skating rink (ice, roller, or inline), swimming pool, walking, biking, or hiking path or trail, tennis court, and dance or gymnastic club. These 14 locations corresponded to recreational activities that similar girls of this age and location reported most often, identified through the formative work of the TAAG Study (Grieser et al., 2006). The responses were scored by adding the total number of facilities to which the participant easily could get to easily (possible score range 0-14). Two-week test-retest reliability, on a separate sample of 6th- and 8th- grade girls, for the physical activity facilities score was 0.78 (intraclass correlation coefficient) (Evenson et al., 2006).

After-school transportation was assessed in the TAAG Study as a potential moderator of the intervention, since parental transportation was previously identified as a barrier to physical activity (Sallis et al., 2000). Girls were also asked the following three questions on afterschool transportation to/from activities, with the response options including not at all difficult, somewhat difficult, very difficult, or impossible.

1. If you stayed after school for an activity everyday, how difficult would it be for you to get home afterward?

2. If you wanted to do an after-school activity someplace else besides school every day, how difficult would it be to get there?

3. If you wanted to do an after-school activity someplace else besides school everyday, how difficult would it be for you to get home afterward?

Two-week test-retest reliability, on a separate sample of 6th- and 8th- grade girls, using the 4-level responses ranged from 0.38-0.44 (weighted kappa coefficients) for these separate items (Evenson et al., 2006).

Covariate Measures-Each girl responded to two questions on race/ethnicity. The first asked whether the girl considered herself as Hispanic, Mexican American, or of Spanish origin. The second asked whether the girl considered herself as white, black or AfricanAmerican, Asian, Native Hawaiian or other Pacific Islander, American Indian or Alaska 
Native, or other. Date of birth was collected on the parental consent forms and age was calculated from the date of birth to the date of completion of the survey. Each school provided the percent of $6^{\text {th }}$, $7^{\text {th }}$-, and $8^{\text {th }}$-graders on free or reduced-price lunches. Generally, students whose families earned less than $200 \%$ of the poverty level were eligible for this program.

A neighborhood socioeconomic index, described elsewhere (Cohen et al., 2006), was created using neighborhood-level U.S. census data. Three different census block-group level indicators from the census were standardized: the percentage of households above the poverty line, the percentage of employed persons in the labor force over 16 years of age, and the percentage of persons over the age of 25 years with more than a high school diploma. These three factors were then combined into an index and interpolated for the circular area delimited by a half-mile radius around each girl's geocoded residence.

\section{Sample Selection and Participation}

Girls were selected within schools by random sampling of all eligible girls. Reasons for ineligibility were: (1) unable to read and understand English, (2) told by a doctor to avoid exercise, or (3) other medical contraindication. A simple random sample of 45 to 60 girls, depending on school size, was drawn from 6th-grade girls in the spring of 2003. Parental consent and student assent were obtained for 1721 of the 2160 eligible girls for an average recruitment rate of $80 \%$.

An independent random sample of 90 to 120 girls, depending on school size, was drawn from eighth-grade girls in the same schools in spring 2005. To maximize the number of girls available for longitudinal studies, we also recruited all of the eighth-grade girls who had been previously measured in the 6th grade and who remained in their original school even if they were not in the second random sample (Stevens et al., 2007).

Of the 1721 girls assessed in 6th grade, 118 had incomplete or missing accelerometer data, 47 home addresses could not be geocoded, and 7 did not complete the $6^{\text {th }}$ grade questionnaire. Following these baseline exclusions, we also excluded 140 girls who moved between baseline and follow-up, 431 girls not measured at follow-up (due to school changes or refusals), and 131 who did not complete the accelerometer portion of data collection in 2005. This left 847 girls for these analyses.

\section{Statistical Analysis}

The data had a hierarchical structure, in which girls were nested within schools and schools were nested within study site. Therefore, to determine whether neighborhood and transport factors were associated with the outcomes, school and site were treated as random effects in a linear mixed model. For these analyses, adjustment for multiple tests was not performed. For all models presented, the normality assumption appeared valid based on examination of the residuals, so that all analyses were performed in the original scale for the dependent variables. We examined two dependent variables: nonschool MW-MVPA and nonschool sedentary behavior, both scaled to minutes/week. For each, we examined 14 measures of neighborhood factors ( 6 safety items, 1 aesthetics item, 3 access to facilities near home items, 1 ease of access to activities scale) and 3 items on transportation.

The longitudinal analysis was conducted in two stages. In the first stage, we performed a mixed-model repeated-measures analysis of covariance (ANCOVA), wherein the dependent variable was regressed on the perceived neighborhood or transportation exposure, time $\left(8^{\text {th }}\right.$ and $6^{\text {th }}$ grade), the interaction between the exposure of interest and time, and the covariates. In each model, the girl-level covariates included race/ethnicity (indicator variables) and neighborhood socioeconomic status (continuous) while the school-level covariates included 
treatment condition (intervention vs. control) and percent free or reduced lunch (continuous).

In the second stage, we selected exposure variables with a p-value of at least $p<0.10$ in the first stage. These variables, time, and their interactions with time were then included in a new mixed-model repeated-measures ANCOVA which also included the design variables and covariates described previously. The time by perceived neighborhood or transportation interactions were dropped one by one until only interactions with $p<0.10$ remained. For categorical exposure variables, we calculated adjusted means for $8^{\text {th }}$ and $6^{\text {th }}$ grade for each category, the $8^{\text {th }}-6^{\text {th }}$ grade change in activity for each category, and contrasts comparing the $8^{\text {th }}-6^{\text {th }}$ grade changes among the categories; the adjusted means were calculated as though each level of exposure had the same average value on each covariate. All analyses were conducted using the MIXED procedure in SAS version 9.1 (Littell et al., 2006).

\section{Results}

\section{Characteristics of the Sample}

Table 1 and 2 summarize the characteristics of the girls included in the analysis sample in the $6^{\text {th }}$ and $8^{\text {th }}$ grades. Approximately half of the participants were White $(53.5 \%)$, followed by Hispanic (19.1\%) and Black (18.0\%). In the 6th grade, the girls mean age was 11.9 years. Nonschool MW-MVPA averaged 703 and 633 MET-minutes/week in the 6th and 8th grades, respectively. Nonschool sedentary behavior averaged 1937 and 2191 minutes/week in the 6th and eighth grades, respectively.

In the $6^{\text {th }}$ and $8^{\text {th }}$ grade, the facilities easiest to get to and from included parks, playing fields, paths or trails, and swimming pools (Table 1). In the $6^{\text {th }}$ grade, more than two-thirds of the sample reported safety walking or jogging in their neighborhood (75.2\%), seeing walkers or bikers from their home $(67.7 \%)$, and seeing other youth playing outdoors in their neighborhood (70.6\%) (Table 3). More than two-thirds of the sample also reported a lot of crime in their neighborhood (77.8\%) and enough traffic to make it hard to walk (79.4\%). Most of these distributions did not meaningfully change from the $6^{\text {th }}$ to the $8^{\text {th }}$ grade.

\section{Longitudinal Findings}

Table 3 summarizes the results of the mixed-model repeated-measures ANCOVA, exploring neighborhood and transportation characteristics measured in the sixth grade on changes in nonschool MW-MVPA from the $6^{\text {th }}$ to $8^{\text {th }}$ grades. The results did not meaningfully change when including the weekday morning times (6:00-9:00am) into the nonschool MW-MVPA measure (data not shown). Of the 14 measures reported by the girls on their neighborhood and transportation tested in the univariable models, four had a global p-value less than 0.10. Of the four, one item (sidewalks on most of the streets in my neighborhood) did not remain significant but the other three remained significant in the multivariable model.

First, in the $6^{\text {th }}$ grade, girls who agreed that their streets were well lit at night had higher nonschool MW-MVPA than girls who disagreed or were neutral. However, between the $6^{\text {th }}$ and $8^{\text {th }}$ grades, those girls had a significant average decline of 93 nonschool MW-MVPA minutes/week. In the $6^{\text {th }}$ grade, those who were neutral that their neighborhood streets were well lit at night had an average significant decline of 119 nonschool MW-MVPA minutes/ week from the $6^{\text {th }}$ to the $8^{\text {th }}$ grade. Those who disagreed did not have any significant change in their nonschool MW-MVPA minutes/week from the $6^{\text {th }}$ to the $8^{\text {th }}$ grade.

We performed contrasts to determine whether the magnitude of the change in nonschool MW-MVPA minutes/week from $6^{\text {th }}$ to $8^{\text {th }}$ grade differed significantly depending on girls' $6^{\text {th }}$ grade response to the statement that their streets were well lit at night (data not shown). 
There were significant differences between girls who disagreed with the other response categories (disagree vs. neither $\mathrm{p}=0.03$; disagree vs. agree $\mathrm{p}=0.03$ ). However the magnitude of decline in nonschool MW-MVPA among girls who agreed (93 minutes/week) and those who were neutral (119 minutes/week) did not differ significantly $(\mathrm{p}=0.67)$.

Second, in the $6^{\text {th }}$ grade, girls who were neutral that they saw other girls or boys playing outdoors in their neighborhood had higher nonschool MW-MVPA than girls who disagreed or agreed. However, between the $6^{\text {th }}$ and $8^{\text {th }}$ grades, those girls had a significant average decline of 217 minutes of nonschool MW-MVPA minutes/week, while those who disagreed with the statement had a significant decline of 106 nonschool MW-MVPA minutes/week. Girls who agreed did not have a significant change in their nonschool MW-MVPA minutes/ week from the $6^{\text {th }}$ to the $8^{\text {th }}$ grade.

We performed contrasts to determine whether the magnitude of the change in nonschool MW-MVPA minutes/week from $6^{\text {th }}$ to $8^{\text {th }}$ grade differed significantly depending on girls' $6^{\text {th }}$ grade response to the statement that they saw other girls or boys playing outdoors in their neighborhood (data not shown). The contrast between those who agreed and those who were neutral was significant ( $\mathrm{p}=0.008$ ). No other contrast was significant.

Third, in the $6^{\text {th }}$ grade, girls who agreed that there were bicycle and walking trails in their neighborhood had higher nonschool MW-MVPA than girls who disagreed or were neutral. However, between the $6^{\text {th }}$ and $8^{\text {th }}$ grades, those girls had a significant average decline of 124 minutes of nonschool MW-MVPA minutes/week. Girls who disagreed, and those who were neutral did not significantly change their nonschool MW-MVPA minutes/week.

Table 4 summarizes the results of the univariable mixed-model repeated-measures ANCOVA exploring neighborhood and transportation characteristics measured in the sixth grade on changes in nonschool sedentary behavior from the $6^{\text {th }}$ to $8^{\text {th }}$ grades. None of the self-reported measures on neighborhood or transportation was related to change in nonschool sedentary behavior (no items with a global p-value $<0.10$ ), so no multivariable analyses were conducted. The results reported in Table 4 did not meaningfully change when including the weekday morning times (6:00-9:00am) into the nonschool sedentary behavior measure (data not shown).

\section{Discussion}

\section{Physical Activity}

This is one of the first longitudinal studies to explore the association of neighborhood characteristics in relationship to changes in objective measures of physical activity and sedentary behavior among adolescent girls. Over this 2-year period, nonschool MW-MVPA declined while sedentary behavior increased, consistent with reports from national surveillance of physical activity using accelerometry (Matthews et al., 2008; Troiano et al., 2008). We hypothesized that girls who perceived a more conducive neighborhood environment for physical activity, more physical activity opportunities, and better transport options at baseline would have more favorable changes from 6th to eighth grade in nonschool physical activity than girls who reported less favorable neighborhood environmental for physical activity, fewer physical activity opportunities, and worse transport options. This hypothesis was based on our prior cross-sectional analysis of this cohort of girls, showing that girls reporting well lit streets, a lot of traffic, presence of bicycle or walking trails, and access to physical activity facilities was associated with nonschool MW-MVPA (Evenson et al., 2007). Since nonschool MW-MVPA declined among this cohort, the term "more favorable changes" in our hypothesis would be classified as a less steep decline in nonschool MW-MVPA as compared to girls reporting less 
favorable neighborhoods for physical activity. This hypothesis was not supported in most cases.

The results for our item on other children playing outside in the neighborhood were consistent with our hypothesis. Disagreeing, or responding neutrally, that other children played outside in their neighborhood was associated with a significant decline in nonschool MW-MVPA. Reporting (i.e., agreeing) in $6^{\text {th }}$ grade that other children played outside in their neighborhood was not associated with a significant change in nonschool MW-MVPA. Children playing outdoors in the neighborhood may be a marker for a more favorable space for youth physical activity and could signal social norms supportive of outdoor physical activity among youth. This measure may be important to assess in other studies, due to the longitudinal associations identified among these adolescent girls.

The results for our item on well lit neighborhood streets were counter to our hypothesis: reporting that the neighborhood had well lit streets was associated with steeper declines in nonschool MW-MVPA. The results for our item on trails in the neighborhood were also counter to our hypothesis: reporting that the neighborhood had trails was associated with a significant decline in nonschool MW-MVPA. It may be the case that both well-lit streets and trails served as important venues for nonschool activity for $6^{\text {th }}$ graders, but not for $8^{\text {th }}$ graders. Also, reporting that there were trails or well lit streets in your neighborhood cannot be interpreted as using the trails or being out at night. In a longitudinal study of North Carolina children from elementary school through the $10^{\text {th }}$ grade, Bradley et al (Bradley et al., 2000) found that girls' most commonly reported after school activities shifted during the middle school years, with sedentary activities such as talking on the phone and music lessons replacing physical activities popular during elementary school such as in-line skating and swimming. Other researchers have found similar replacement of active pursuits with sedentary leisure activities over time among adolescents (Aaron et al., 2002; Dovey et al., 1998). If similar substitutions occurred in our sample, this could explain to the observed associations.

The remaining four safety items, the aesthetics item, and the three transportation items were not associated with changes in nonschool MW-MVPA. This pattern is actually consistent with the few other longitudinal studies of youth that included neighborhood measures. A study among high school girls found that a 3-item measure relating to cost and lack of physical activity resources was not associated with changes in self-reported physical activity (Neumark-Sztainer et al., 2003). In younger age groups, no association in changes of selfreported physical activity were observed for home equipment (Trost et al., 1997) and parental reported neighborhood safety (Sallis et al., 1999).

These findings raise interesting questions about our understanding of the relationship between neighborhoods and physical activity for adolescents. Positive associations have been found in cross-sectional studies, including our own. But longitudinal studies have found few associations, and sometimes associations that were counter to expectations. One possible explanation is that the relationships change as children age. Another is that the activity itself leads to change both in the activity and in the relationship. For example, children who engage in physical activity outdoors may be more likely to notice and report characteristics such as dangerous locations and unpleasant smells simply because their outdoor activity gives them greater exposure to those characteristics than their peers who are less active outdoors.

\section{Sedentary Behavior}

We found no associations between 14 separate measures on the girl's neighborhood and transportation with changes in nonschool sedentary behavior. Previously, we also did not 
identify any cross-sectional associations between measures of the girl's neighborhood and nonschool sedentary behavior (Evenson et al., 2007) and we are not aware of other longitudinal studies with which to compare our findings. For these middle school girls, it appears that the self-reported neighborhood measures we investigated did not impact sedentary behavior; it may be that intrapersonal and interpersonal factors may be more important for sedentary behavior. This highlights the point that correlates and determinants of physical activity may differ from those for sedentary behavior. In a review among youth, the authors found that some variables that are consistent positive correlates of physical activity, such as self-efficacy, did not always have the opposite association with sedentary behavior (Van Der Horst et al., 2007). Moreover, sedentary behavior and physical activity may not be associated with each other, supporting the hypothesis that some variables may not be correlates of both behaviors (Sallis et al., 2000; Van Der Horst et al., 2007).

\section{Limitations and Strengths}

This study is limited by several factors. While we included diverse girls from six different states, there was loss to follow-up and thus, loss of generalizability. Replication of results is needed. We cannot rule out the potential of regression to the mean to account for some of these longitudinal findings, as the largest declines were generally observed among girls whose initial levels of the dependent variable were highest. It is important to note that the measure of access to physical activity facilities related to spatial features (e.g., proximity, density) and ignored specific features of those facilities, including aesthetics, safety, cost, and age-appropriate offerings. Further refinement of this simple measure might prove useful. Moreover, some of the self-reported items under study showed only moderate test-retest reliability from our pilot work (Evenson et al., 2006). To account for this, we collapsed some measures into fewer categories. It is not known if the changes we found associated with nonschool MW-MVPA may be due to concurrent changes in perceptions of the neighborhoods. Due to the timing of the measures in these data, to explore changes in perceptions of the neighborhoods to changes in the outcome would essentially reduce the analyses to a cross-sectional examination so this was not explored.

Many of the prior cross-sectional studies and all of the prior longitudinal studies used selfreported physical activity or sedentary measures, rather than objective measures. While the objective measures have notable strengths, including removal of recall bias and improved precision by focusing on nonschool time, the derived outcomes we used (nonschool MWMVPA and sedentary behavior) were not specific to a type and location of activity or behavior, which may also account for some of our null findings. For example it may be that rather than a focus on MVPA, the more relevant measures for the neighborhood are specific to walking, bicycling, or physical activities done outdoors. Other studies could consider the use of pedometers (also available using accelerometry) and global positioning system (GPS) to help further refine the physical activity outcome measures. This approach of specificity has been advocated by others (Giles-Corti et al., 2005). Other strengths of this study include the diverse sample of girls and the prospective study design.

\section{Conclusion}

Among adolescent girls, we found that nonschool physical activity declined and sedentary behavior increased from the $6^{\text {th }}$ to the $8^{\text {th }}$ grade. We hypothesized that declines in nonschool physical activity and increases in nonschool sedentary behavior would be less pronounced in girls who at baseline reported neighborhood characteristics favorable to physical activity. Only limited support for this hypothesis was found. Reporting that other children play outdoors in the neighborhood was protective against a significant decline in nonschool MWMVPA. However, counter to expectations, reporting that the neighborhood was well lit at night and that there were bicycle or walking trails in the neighborhood were each associated 
with significant declines in nonschool MW-MVPA. The remaining neighborhood and transportation measures were not associated with changes in nonschool MW-MVPA and none of the factors explored were associated with changes in nonschool sedentary behavior. Further work is needed to understand the determinants of the decline in physical activity and the increase in sedentary behavior among adolescent girls. In particular, it may be important to understand differences between adolescents and adults in how neighborhood characteristics relate to physical activity and sedentary behavior.

\section{Acknowledgments}

This work was funded by NIH/NHLBI Grants \#R01HL071244, U01HL-66845, HL-066852, HL-066853, HL-066855, HL-066856, HL-066857, and HL-066858. We thank the girls who participated in the study; the project coordinators for participant recruitment; and the members of TAAG Steering Committee, including: Russell Pate, Ph.D., University of South Carolina; Deborah Rohm-Young, Ph.D., University of Maryland College Park; Leslie Lytle, Ph.D., University of Minnesota; Timothy Lohman, Ph.D., University of Arizona; Larry Webber, Ph.D., Tulane University; John Elder, Ph.D., San Diego State University; June Stevens, Ph.D., The University of North Carolina at Chapel Hill; and Charlotte Pratt, Ph.D., National Heart, Lung, and Blood Institute. The authors thank Christine Cox for help with earlier analyses and Leslie Lytle's review of an earlier draft of this paper.

\section{References Cited}

Aaron D, Storti K, Robertson R, Kriska A, LaPorte R. Longitudinal study of the number and choice of leisure time physical activities from mid to late adolescence. Arch Pediatr Adolesc Med 2002;156:1075-1080. [PubMed: 12413332]

Biddle S, Whitehead S, O'Donovan T, Nevill M. Correlates of participation in physical activity for adolescent girls: a systematic review of recent literature. J Phys Act Health 2005;2:423-434.

Bradley C, McMurray R, Harrell J, Deng S. Changes in common activities of 3rd through 10th graders: the CHIC study. Med Sci Sports Exerc 2000Z;32:2071-2078. [PubMed: 11128854]

Brownson R, Boehmer T, Luke D. Declining rates of physical activity in the United States: What are the contributors? Annu Rev Public Health 2005;26:421-443. [PubMed: 15760296]

Catellier DJ, Hannan PJ, Murray DM, Addy CL, Conway TL, Yang S, Rice JC. Imputation of missing data when measuring physical activity by accelerometry. Med Sci Sports Exerc 2005;37:S555S562. [PubMed: 16294118]

Cohen D, Ashwood S, Scott M, Overton A, Evenson K, Voorhees C, Bedimo-Rung A, McKenzie T. Proximity to school and physical activity among middle school girls: The Trial of Activity in Adolescent Girls Study. J Physical Activity Health 2006;3 Suppl 1:S129-S138.

Davison K, Lawson C. Do attributes in the physical environment influence children's physical activity? A review of the literature. Intl J Behavioral Nutr Physical Activity 2006;3:1-17.

Dovey S, Reeder A, Chalmers D. Continuity and change in sporting and leisure time physical activities during adolescence. Br J Sports Med 1998;32:53-57. [PubMed: 9562165]

Elder JP, Shuler L, Moe SG, Grieser M, Pratt C, Cameron S, Hingle M, Pickrel JL, Saksvig BI, Schachter K, Greer S, Guth Bothwell EK. Recruiting a diverse group of middle school girls into the trial of activity for adolescent girls. J Sch Health 2008;78:523-531. [PubMed: 18808471]

Evenson K, Birnbaum A, Bedimo-Rung A, Sallis J, Voorhees C, Ring K, Elder J. Girl's perception of physical environmental factors and transportation access: Reliability and association with physical activity and active transport to school. Intl J Behavioral Nutr Physical Activity 2006;3 Accessed at www.ijbnpa.org/content/3/1/28.

Evenson K, Scott M, Cohen D, Voorhees C. Girls' perception of neighborhood factors on physical activity, sedentary behavior, and BMI. Obesity 2007;15:430-445. [PubMed: 17299117]

Ferreira I, van der Horst K, Wendel-Vos W, Kremers S, van Lenthe F, Brug J. Environmental correlates of physical activity in youth - a review and update. Obes Rev 2007;8:129-154. [PubMed: 17300279]

Giles-Corti B, Timperio A, Bull F, Pikora T. Understanding physical activity environmental correlates: increased specificity for ecological models. Exerc Sport Sci Rev 2005;33:175-181. [PubMed: 16239834] 
Grieser M, Vu M, Bedimo-Rung A, Neumark-Sztainer D, Moody J, Rohm Young D, Moe S. Physical activity attitudes, preferences, and practices in African American, Hispanic, and Caucasian girls. Health Educ Behav 2006;33:40-51. [PubMed: 16397158]

Littell, R.; Milliken, G.; Stroup, W.; Wolfinger, R.; Schabenberger, O. SAS for Mixed Models. Second Edition. Cary, North Carolina: SAS Institute; 2006.

Matthews C, Chen K, Freedson P, Buchowski M, Beech B, Pate R, Troiano R. Amount of time spent in sedentary behaviors in the United States, 2003-2004. Am J Epidemiol 2008;167:875-881. [PubMed: 18303006]

McLeroy K, Bibeau D, Steckler A, Glanz K. An ecological perspective on health promotion programs. Health Educa Q 1988;15:351-377.

Metcalf B, Curnow J, Evans C, Voss L, Wilkin T. Technical reliability of the CSA activity monitor: The EarlyBird Study. Med Sci Sports Exerc 2002;34:1533-1537. [PubMed: 12218751]

Nader PR, Bradley RH, Houts RM, McRitchie SL, O'Brien M. Moderate-to-vigorous physical activity from ages 9 to 15 years. JAMA 2008;300:295-305. [PubMed: 18632544]

Neumark-Sztainer D, Story M, Hannan P, Tharp T, Rex J. Factors associated with changes in physical activity: a cohort study of inactive adolescent girls. Arch Pediatr Adolesc Med 2003;157:803-810. [PubMed: 12912787]

Sallis J, Alcaraz J, McKenzie T, Hovell M. Predictors of change in children's physical activity over 20 months. Am J Prev Med 1999;16:222-229. [PubMed: 10198662]

Sallis, J.; Owen, N. Ecological models. In: Glanz, K.; Lewis, FM.; Rimer, BK., editors. Health Behavior and Health Education: Theory, Research, and Practice. 2nd ed.. San Francisco, CA: Jossey-Bass; 1997. p. 403-424.

Sallis J, Prochaska J, Taylor W. A review of correlates of physical activity of children and adolescents. Med Sci Sports Exerc 2000;32:963-975. [PubMed: 10795788]

Schmitz KH, Treuth M, Hannan P, McMurray R, Ring KB, Catellier D, Pate R. Predicting energy expenditure from accelerometry counts in adolescent girls. Med Sci Sports Exerc 2005;37:155161. [PubMed: 15632682]

Stevens J, Murray D, Catellier D, Lytle L, Elder J, Young D, Simons-Morton D, Webber L. Design of the Trial of Activity in Adolescent Girls (TAAG). Contemporary Clin Trials 2005;26:223-233.

Stevens J, Murray DM, Baggett CD, Elder JP, Lohman TG, Lytle LA, Pate RR, Pratt CA, Treuth MS, Webber LS, Young DR. Objectively assessed associations between physical activity and body composition in middle-school girls: the Trial of Activity for Adolescent Girls. Am J Epidemiol 2007;166:1298-1305. [PubMed: 17855391]

Tester JM. The built environment: designing communities to promote physical activity in children. Pediatrics 2009;123:1591-1598. [PubMed: 19482771]

Treuth M, Schmitz K, Catellier D, McMurray R, Murray D, Almeida M, Going S, Norman J, Pate R. Defining accelerometer thresholds for activity intensities in adolescent girls. Med Sci Sports Exerc 2004;36:1259-1266. [PubMed: 15235335]

Troiano R, Berrigan D, Dodd K, Masse L, Tilert T, McDowell M. Physical activity in the United States measured by accelerometer. Med Sci Sports Exerc 2008;40:181-188. [PubMed: 18091006]

Trost SG, Pate RR, Saunders R, Ward DS, Dowda M, Felton G. A prospective study of the determinants of physical activity in rural fifth-grade children. Prev Med 1997;26:257-263. [PubMed: 9085396]

Van Der Horst K, Paw MJ, Twisk JW, Van Mechelen W. A brief review on correlates of physical activity and sedentariness in youth. Med Sci Sports Exerc 2007;39:1241-1250. [PubMed: 17762356]

Webber LS, Catellier DJ, Lytle LA, Murray DM, Pratt CA, Young DR, Elder JP, Lohman TG, Stevens J, Jobe JB, Pate RR. Promoting physical activity in middle school girls Trial of Activity for Adolescent Girls. Am J Prev Med 2008;34:173-184. [PubMed: 18312804] 
Table 1

Characteristics of participants in the 6th and 8 th grade $(n=847)$

\begin{tabular}{|c|c|c|c|c|}
\hline & \multicolumn{2}{|c|}{ 6th grade } & \multicolumn{2}{|c|}{ 8th grade } \\
\hline & Percent & $\mathbf{n}$ & Percent & $\mathbf{n}$ \\
\hline \multicolumn{5}{|l|}{ Site } \\
\hline Tucson, AZ & 14.9 & 126 & & \\
\hline San Diego, CA & 17.8 & 151 & & \\
\hline Baltimore, MD & 16.5 & 140 & & \\
\hline New Orleans, LA & 14.5 & 123 & & \\
\hline Minneapolis, MN & 23.0 & 195 & & \\
\hline Columbia, SC & 13.2 & 112 & & \\
\hline \multicolumn{5}{|l|}{ Race/ethnicity } \\
\hline Asian, Native Hawaiian or Pacific Islander & 4.8 & 41 & & \\
\hline Black & 18.0 & 152 & & \\
\hline American Indian & 0.2 & 2 & & \\
\hline Multi-racial & 4.4 & 37 & & \\
\hline Hispanic & 19.1 & 162 & & \\
\hline White & 53.5 & 453 & & \\
\hline \multicolumn{5}{|l|}{ Is it easy to get to and from a .... (yes) } \\
\hline basketball court & 59.4 & 482 & 70.0 & 589 \\
\hline beach or lake & 31.3 & 254 & 32.7 & 275 \\
\hline golf course & 26.5 & 214 & 32.6 & 274 \\
\hline health club & 23.3 & 188 & 36.4 & 304 \\
\hline martial arts studio & 21.5 & 173 & 26.8 & 225 \\
\hline playing field & 71.7 & 583 & 78.2 & 655 \\
\hline park & 74.4 & 607 & 83.3 & 700 \\
\hline recreation center & 33.5 & 270 & 44.3 & 372 \\
\hline track & 45.2 & 359 & 57.8 & 481 \\
\hline skating rink (ice, roller, or inline) & 37.7 & 300 & 40.9 & 341 \\
\hline swimming pool & 64.5 & 513 & 67.3 & 560 \\
\hline walking, biking, or hiking path or trail & 63.9 & 508 & 64.8 & 540 \\
\hline tennis court & 48.1 & 381 & 60.7 & 504 \\
\hline dance or gymnastics club & 31.4 & 248 & 35.7 & 297 \\
\hline
\end{tabular}

Health Place. Author manuscript; available in PMC 2011 September 1. 
Table 2

Mean and standard deviation (SD) of measures describing participants in the 6th and 8th grade $(n=847)$

\begin{tabular}{lcccccc}
\hline & \multicolumn{2}{c}{ 6th grade } & & \multicolumn{2}{c}{ 8th grade } \\
\cline { 2 - 3 } & Mean & SD & & Mean & SD \\
\hline Age & 11.9 & 0.4 & & 13.9 & 0.4 \\
*Access to physical activity facilities sum score: & 6.2 & 3.3 & 7.3 & 3.2 \\
Percent free and reduced lunch (school-level) & 34.0 & 25.9 & 37.9 & 26.2 \\
Standardized socioeconomic status index & 0.2 & 0.9 & & 0.2 & 0.9 \\
**Weekly nonschool activity from accelerometer: & & & & \\
Sedentary minutes per week & 1937 & 369 & & 2191 & 352 \\
MW-MVPA minutes per week & 703 & 476 & 633 & 408 \\
\hline
\end{tabular}

* Access to physical activity facilities sum score combines the total number of physical activity facilities easy to get to. **

After 2pm on weekdays, in addition to the weekend.

MW-MVPA: MET-weighted moderate to vigorous physical activity 


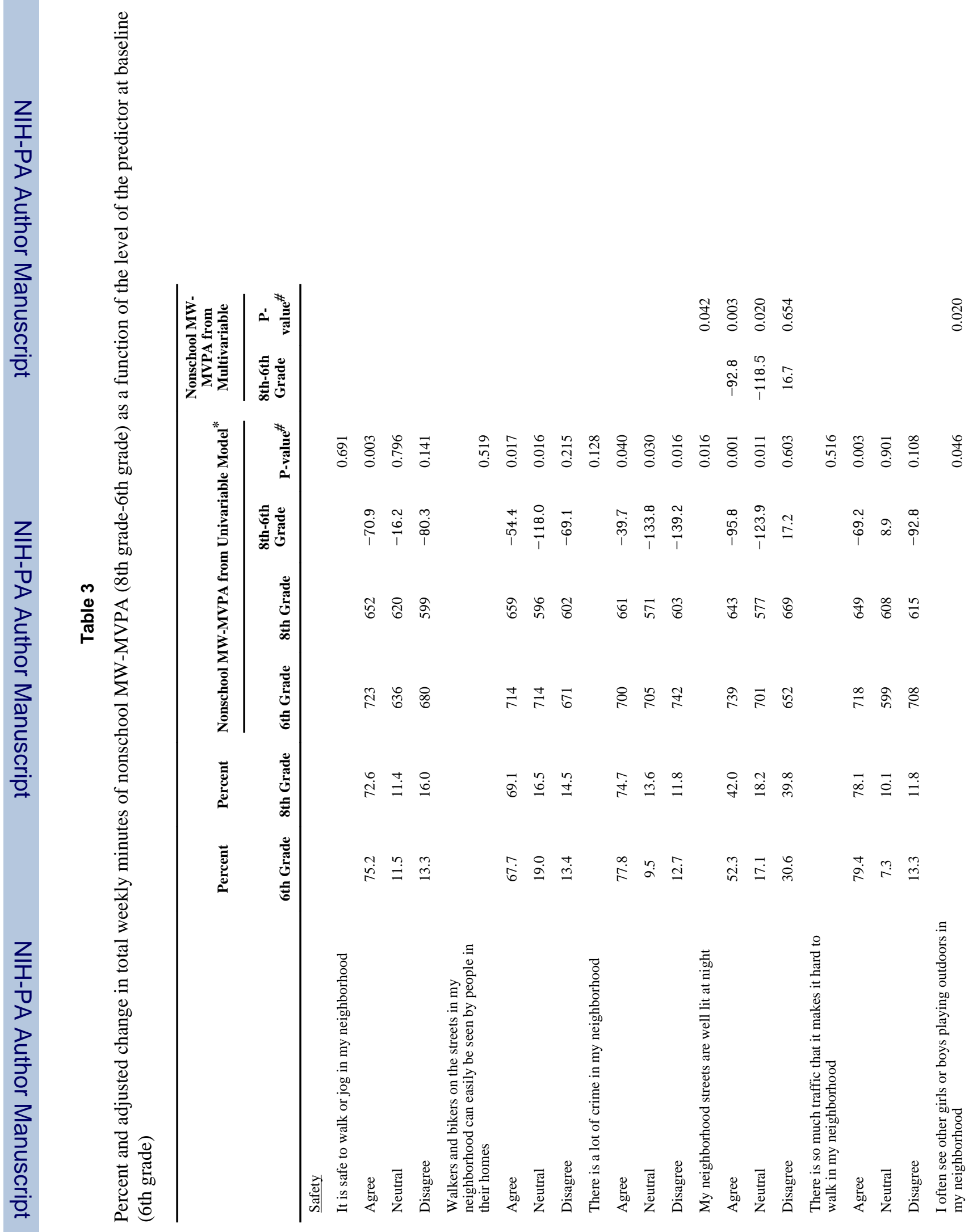

Health Place. Author manuscript; available in PMC 2011 September 1. 


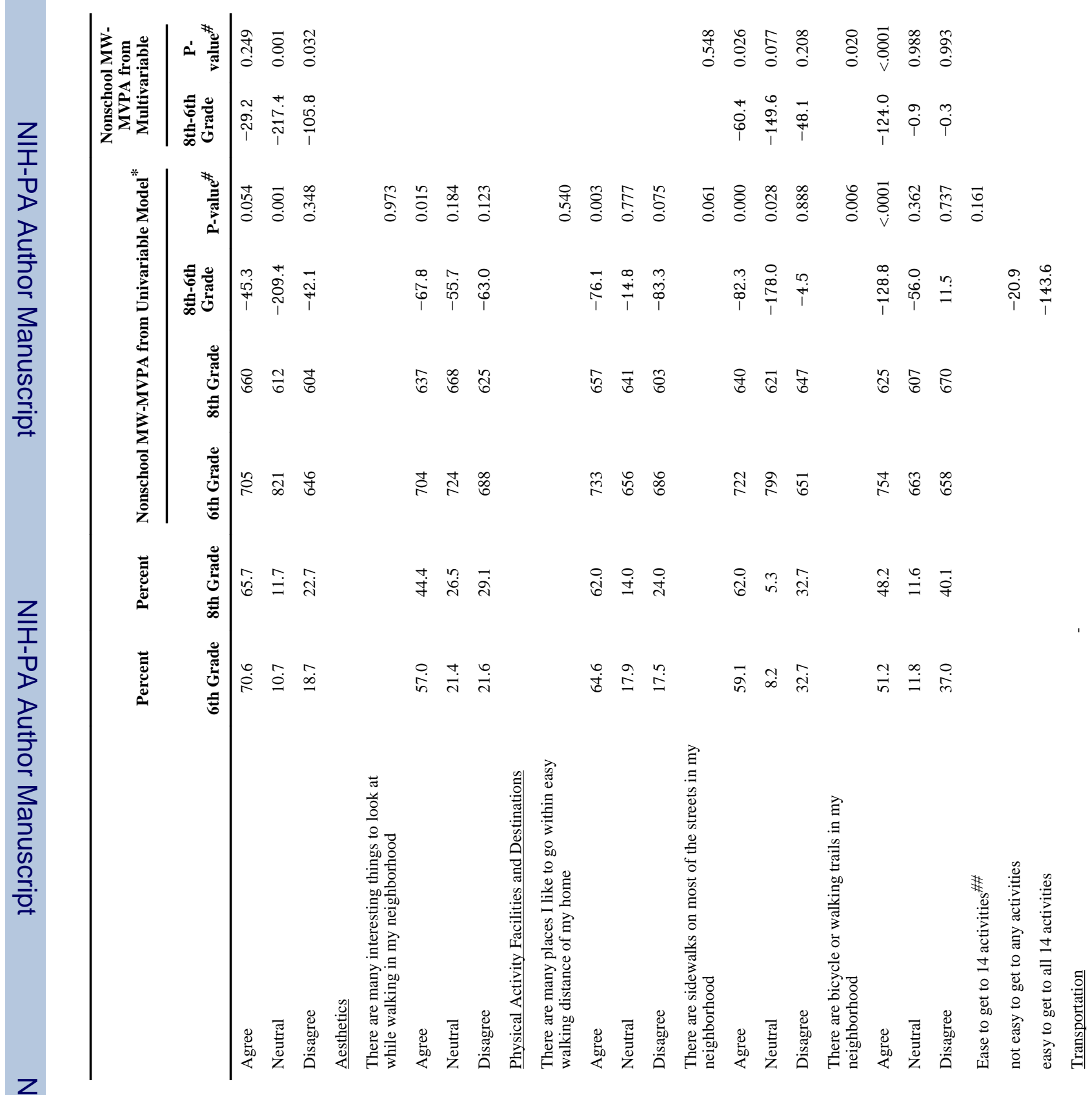

Health Place. Author manuscript; available in PMC 2011 September 1. 


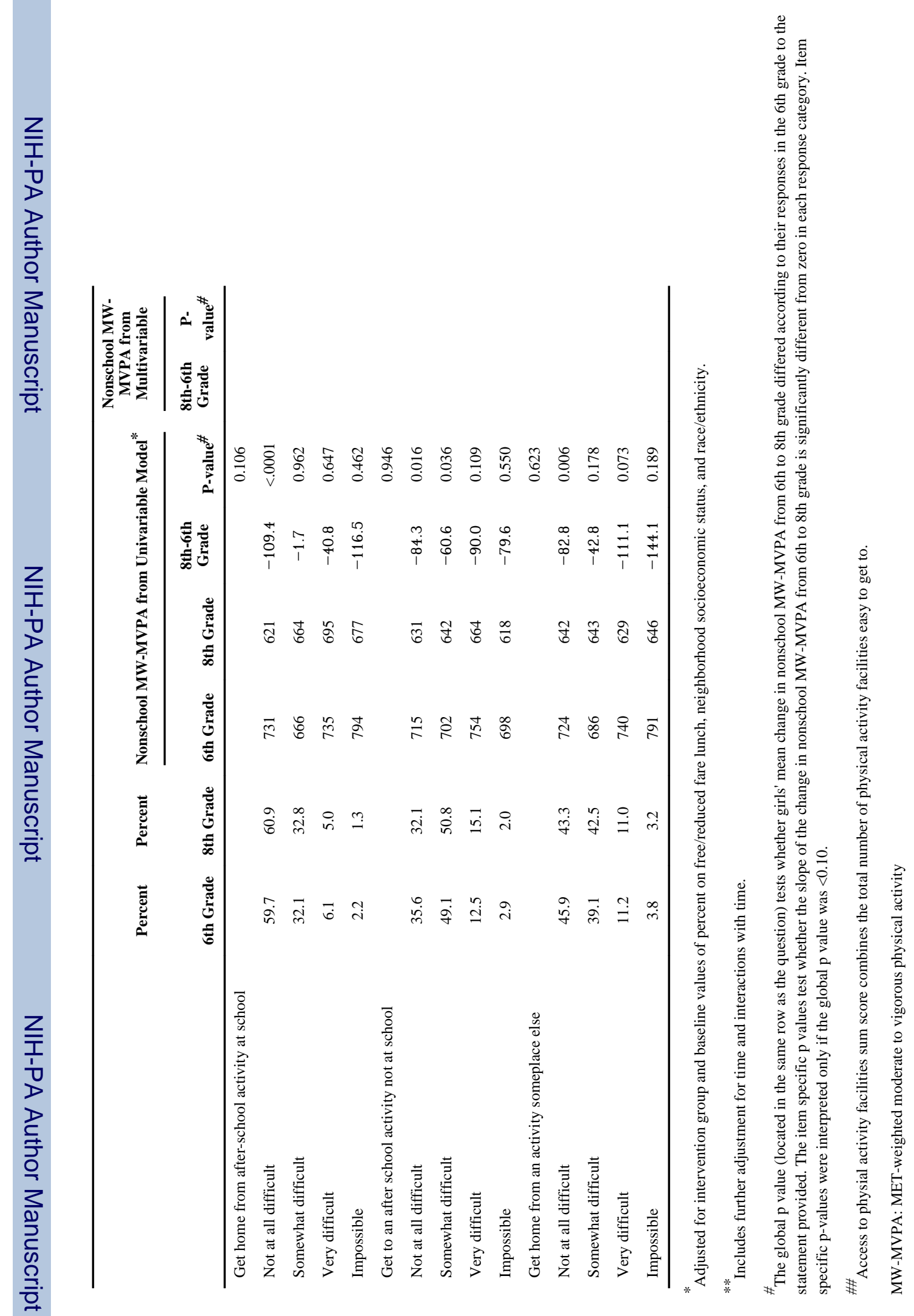

Health Place. Author manuscript; available in PMC 2011 September 1. 
Table 4

Adjusted change in total weekly minutes of nonschool sedentary behavior (8th grade-6th grade) as a function of the level of the predictor at baseline (6th grade)

\begin{tabular}{|c|c|c|c|c|}
\hline & \multicolumn{4}{|c|}{$\begin{array}{l}\text { Nonschool sedentary behavior from univariable } \\
\text { models }\end{array}$} \\
\hline & 6th Grade & 8th Grade & 8th-6th Grade & P-value ${ }^{\#}$ \\
\hline \multicolumn{5}{|l|}{ Safety } \\
\hline It is safe to walk or jog in my neighborhood & & & & 0.616 \\
\hline Agree & 1943 & 2184 & 240.9 & $<.0001$ \\
\hline Neutral & 1926 & 2200 & 274.4 & $<.0001$ \\
\hline Disagree & 1896 & 2179 & 282.5 & $<.0001$ \\
\hline $\begin{array}{l}\text { Walkers and bikers on the streets in my neighborhood } \\
\text { can easily be seen by people in their homes }\end{array}$ & & & & 0.183 \\
\hline Agree & 1953 & 2176 & 222.8 & $<.0001$ \\
\hline Neutral & 1896 & 2198 & 302.0 & $<.0001$ \\
\hline Disagree & 1926 & 2191 & 264.6 & $<.0001$ \\
\hline There is a lot of crime in my neighborhood & & & & 0.877 \\
\hline Agree & 1947 & 2190 & 243.3 & $<.0001$ \\
\hline Neutral & 1918 & 2189 & 271.2 & $<.0001$ \\
\hline Disagree & 1887 & 2132 & 245.1 & $<.0001$ \\
\hline My neighborhood streets are well lit at night & & & & 0.266 \\
\hline Agree & 1926 & 2160 & 234.1 & $<.0001$ \\
\hline Neutral & 1932 & 2236 & 303.8 & $<.0001$ \\
\hline Disagree & 1954 & 2182 & 228.5 & $<.0001$ \\
\hline $\begin{array}{l}\text { There is so much traffic that it makes it hard to walk in } \\
\text { my neighborhood }\end{array}$ & & & & 0.282 \\
\hline Agree & 1941 & 2193 & 252.1 & $<.0001$ \\
\hline Neutral & 1985 & 2148 & 162.3 & 0.011 \\
\hline Disagree & 1870 & 2145 & 275.0 & $<.0001$ \\
\hline $\begin{array}{l}\text { I often see other girls or boys playing outdoors in my } \\
\text { neighborhood }\end{array}$ & & & & 0.940 \\
\hline Agree & 1943 & 2188 & 245.4 & $<.0001$ \\
\hline Neutral & 1913 & 2142 & 229.4 & $<.0001$ \\
\hline Disagree & 1929 & 2180 & 251.1 & $<.0001$ \\
\hline \multicolumn{5}{|l|}{ Aesthetics } \\
\hline $\begin{array}{l}\text { There are many interesting things to look at while walking } \\
\text { in my neighborhood }\end{array}$ & & & & 0.269 \\
\hline Agree & 1939 & 2158 & 218.7 & $<.0001$ \\
\hline Neutral & 1923 & 2206 & 283.8 & $<.0001$ \\
\hline Disagree & 1940 & 2198 & 258.1 & $<.0001$ \\
\hline \multicolumn{5}{|l|}{ Physical Activity Facilities and Destinations } \\
\hline $\begin{array}{l}\text { There are many places I like to go within easy walking } \\
\text { distance of my home }\end{array}$ & & & & 0.365 \\
\hline Agree & 1923 & 2176 & 253.4 & $<.0001$ \\
\hline
\end{tabular}




\begin{tabular}{|c|c|c|c|c|}
\hline & \multicolumn{4}{|c|}{$\begin{array}{l}\text { Nonschool sedentary behavior from univariable } \\
\text { models }\end{array}$} \\
\hline & 6th Grade & 8th Grade & 8th-6th Grade & P-value \\
\hline Neutral & 1945 & 2135 & 189.3 & 0.000 \\
\hline Disagree & 1966 & 2225 & 258.8 & $<.0001$ \\
\hline $\begin{array}{l}\text { There are sidewalks on most of the streets in my } \\
\text { neighborhood }\end{array}$ & & & & 0.594 \\
\hline Agree & 1930 & 2182 & 251.4 & $<.0001$ \\
\hline Neutral & 1890 & 2070 & 180.3 & 0.012 \\
\hline Disagree & 1956 & 2203 & 246.3 & $<.0001$ \\
\hline There are bicycle or walking trails in my neighborhood & & & & 0.921 \\
\hline Agree & 1928 & 2181 & 252.6 & $<.0001$ \\
\hline Neutral & 1959 & 2190 & 230.7 & $<.0001$ \\
\hline Disagree & 1939 & 2184 & 245.3 & $<.0001$ \\
\hline Ease to get to 14 activities $\# \#$ & & & & 0.918 \\
\hline not easy to get to any activities & & & 256.5 & \\
\hline easy to get to all 14 activities & & & 249.0 & \\
\hline \multicolumn{5}{|l|}{ Transportation } \\
\hline Get home from after-school activity at school & & & & 0.906 \\
\hline Not at all difficult & 1929 & 2175 & 246.4 & $<.0001$ \\
\hline Somewhat difficult & 1945 & 2205 & 259.6 & $<.0001$ \\
\hline Very difficult & 1968 & 2197 & 228.9 & 0.003 \\
\hline Impossible & 1895 & 2069 & 174.6 & 0.182 \\
\hline Get to an after school activity not at school & & & & 0.845 \\
\hline Not at all difficult & 1924 & 2176 & 252.7 & $<.0001$ \\
\hline Somewhat difficult & 1939 & 2175 & 235.5 & $<.0001$ \\
\hline Very difficult & 1955 & 2232 & 277.1 & $<.0001$ \\
\hline Impossible & 1954 & 2163 & 208.6 & 0.061 \\
\hline Get home from an activity someplace else & & & & 0.868 \\
\hline Not at all difficult & 1921 & 2156 & 235.8 & $<.0001$ \\
\hline Somewhat difficult & 1948 & 2206 & 258.1 & $<.0001$ \\
\hline Very difficult & 1956 & 2190 & 234.0 & $<.0001$ \\
\hline Impossible & 1927 & 2221 & 294.3 & 0.002 \\
\hline
\end{tabular}

* Adjusted for intervention group and baseline values of percent on free/reduced fare lunch, neighborhood socioeconomic status, and race/ethnicity.

\# The global p value (located in the same row as the question) tests whether girls' mean change in nonschool sedentary behavior from 6th to 8th grade differed according to their responses in the 6th grade to the statement provided. The item specific $p$ values test whether the slope of the change in nonschool sedentary behavior from 6th to 8 th grade is significantly different from zero in each response category. Item specific p-values were interpreted only if the global $\mathrm{p}$ value was $<0.10$

${ }^{\# \#}$ Access to physial activity facilities sum score combines the total number of physical activity facilities easy to get to. 